\title{
AVALIAÇÃO DA MODA PRAIA FEMININA DO RIO DE JANEIRO NA PERSPECTIVA DO MIX DE MARKETING
}

\section{ARTIGO ORIGINAL}

SANTIAGO, Bruna da Silva ${ }^{1}$

SANTIAGO, Bruna da Silva. Avaliação da moda praia feminina do Rio de Janeiro na perspectiva do mix de marketing. Revista Científica Multidisciplinar Núcleo do Conhecimento. Ano 05, Ed. 03, Vol. 01, pp. 05-17. Março de 2020. ISSN: 2448-0959, Link de acesso: https://www.nucleodoconhecimento.com.br/marketing/avaliacao-damoda-praia

\section{RESUMO}

O presente trabalho tem por objetivo traçar uma análise da moda praia feminina carioca frente ao mix de maketing (4 Ps). Foi realizado um estudo de caso da marca de moda praia carioca Zillê Rio para identificação de perfis, e, para tanto, considerouse o público-alvo de roupas femininas de banho. A fim de coletar as respostas, realizou-se entrevistas com a gestora e funcionárias. Em seguida, foram feitas entrevistas com o público-alvo a fim de explorar hábitos comportamentais e de consumo. Por fim, apurou-se que os hábitos dos perfis identificados referentes aos 4Ps mudam de acordo com a faixa etária, sendo este o resultado deste artigo.

Palavras-chave: Moda Praia, mix de marketing, comportamento feminino, faixa etária.

\section{INTRODUÇÃO}

A moda sempre é um fenômeno de costume, e assim, pode-se dizer que existe moda quando o amor pelo novo se torna um princípio constante, um hábito, uma exigência cultural (CALANCA, 2008). A moda é um fator cíclico, que muda de geração para

\footnotetext{
1 Pós-Graduação em Gestão de Negócios, Pós-Graduação em Gestão de Pessoas, Graduação em Administração de Empresas PUC-Rio.
} 
geração com o passar dos anos. Isso move a economia global, devido à necessidade dos indivíduos de se ajustarem aos padrões de consumo pregados pelas mídias sociais. Esse padrão se estende para moda praia e suas diversas alterações, sofridas ao longo dos séculos desde sua invenção. Mudanças nos modelos e padrões de beleza dessas peças se ajustam aos fatores psicossociais dos indivíduos e se referem a estilo de vida, classe social, idade, gostos e preferências. O público-alvo é a parte do mercado disponível qualificado, conforme definido por Nickels e Wood (1999, p. 329), público-alvo é "o grupo de pessoas que a mensagem de marketing pretende atingir".

Este artigo tem a finalidade de verificar como o público feminino consumidor desses produtos se comporta frente ao mix de marketing. Para atingir esse propósito, foi realizada uma pesquisa qualitativa cujo foco foi a empresa de moda praia Zillê Rio. A pesquisa teve como objetivo investigar os hábitos de consumo, formas de compra e meios de comunicação, e, para isso, realizou-se entrevistas com o público-alvo, gestora e funcionárias da empresa durante o primeiro semestre de 2019. O conceito de mix de marketing foi idealizado por Neil Borden e estabelecido por Jerome McCarthy. Definiu-se 4 grupos de atividades do mercado: produto, preço, praça e promoção, também chamado de "4 Ps" (KOTLER, 1998). Esta pesquisa teve como objetivo identificar perfis dentro do público consumidor feminino de moda praia frente ao mix de marketing de uma empresa do setor.

Pretendeu-se, ainda, analisar a existência de diferenças de hábitos no caso de mulheres com ou sem filhos. Este estudo é relevante para os acadêmicos e empresários que tenham interesse nesse segmento, visto que envolve hábitos de consumo e o mix de marketing. O diferencial desse trabalho é que, a partir dos dados coletados, identificou-se os hábitos de consumo de perfis por meio de três faixas etárias. Essas ações são referentes a diretrizes estabelecidas no composto dos 4 Ps de marketing. A participação da Zillê Rio serviu como uma importante fonte de informação para pesquisa. O público-alvo foi definido pela gestora para a expansão da marca. A Zillê serviu como base para identificar os perfis e as entrevistas e ambos 
foram traçados tendo-se como objetivo mapear os 4Ps e identificar o comportamento de clientes do público-alvo feminino que consomem esses artigos.

\section{REFERENCIAL TEÓRICO}

Kotler (1998), afirma que a tarefa do departamento de marketing de uma empresa é delinear atividades da área e montar programas integrados para criar, comunicar e entregar valor aos consumidores. Uma maneira tradicional de se avaliar uma empresa para se chegar a um diagnóstico é analisar o mix de marketing. Esse conceito corresponde a um conjunto de ferramentas que serve para a empresa avaliar, nortear e considerar seus objetivos. Elias (2000), esclarece que o composto mercadológico (mix de marketing) foi formulado primeiramente por Jerome McCarthy, em seu livro Basic Marketing (1960), e trata do conjunto de pontos de interesse para os quais as organizações devem estar atentas, se desejam perseguir seus objetivos. Este modelo se baseia na ideia de que a empresa produz um bem ou serviço (produto), e, assim, o consumidor deve ser comunicado de sua existência (promoção), deve haver a distribuição dos mais variados tipos e locais de venda (praça) e a empresa precisa cobrar um montante pelo fornecimento do bem ou serviço (preço).

A função de marketing referente ao mix engloba as decisões do produto, incluindo a identificação de oportunidades de lançamento de produtos e adequação dos mesmos às necessidades dos clientes; as decisões de preço, que deve ser estabelecido para gerar vantagem competitiva e retorno para a empresa; as decisões de promoção, relativas aos investimentos em estratégias de comunicação e promoção de vendas e as decisões de praça ou distribuição, que envolvem a escolha de canais de vendas que satisfaçam as necessidades dos clientes (GONÇALVES et al, 2008). O conceito original da roupa de banho em duas peças separadas foi desenvolvido pelo estilista francês Louis Réard e a escolha do nome biquíni foi, de acordo com Garcia (2010), a maneira encontrada para protestar contra a série de testes atômicos realizados pelos Estados Unidos no pequeno Atol de Biquini, localizado no Pacífico. Devido às críticas recebidas pela imprensa da época, o biquíni não obteve uma aceitação imediata pela população. 
Ao realizar a comparação do primeiro modelo (todo em algodão com estamparia imitando a página de um jornal) com os modelos atuais, verificou-se uma sensível evolução no estilo e modelagem em oposição a uma vasta disponibilidade de tecidos e de estamparia para a confecção desse tipo de produto (MARQUES, 2004). Há mais inovações de materiais do que de modelagens ao longo de sua história. Conforme a Revista Manequim (2010), a tecnologia dos tecidos atualmente utilizada para a confecção da moda praia propicia, em algumas determinadas composições, a adoção de conceitos tecnológicos que possibilitam a secagem rápida, impedindo a proliferação de bactérias e protegendo a pele contra os raios ultravioletas. Nos anos 2000, verificou-se algumas das principais inovações com lançamentos de materiais têxteis para este segmento. Dentre eles se destacou a tecnologia do Lycra® Xtra Life, que dá uma maior longevidade ao fio do tecido e permite conservar as formas de biquínis, maiôs e sungas até três vezes mais que o tradicional elastano, utilizado nos anos de 1990.

O setor de moda é um mercado em ascensão no Brasil, e, assim, possui oportunidades de trabalho diversas, sendo fundamental para mover a economia no país. Segundo projeções, esse mercado no Rio de Janeiro deve crescer até 2023 cerca de 5,6\% (RODRIGUES, 2018). O setor produtivo da moda no Rio de Janeiro possui cerca de 5 mil indústrias gerando 70 mil empregos, segundo a Federação da Indústrias do Estado do Rio de Janeiro (FIRJAM, 2018). Considerando a cadeia como um todo, incluindo o comércio, são contabilizados quase 26 mil estabelecimentos. Trata-se de uma área que reagiu com rapidez à crise econômica que se instalou no estado em 2014 e vem se fixando como um importante indutor da retomada do crescimento (SEBRAE, 2018). Dados do Serviço Brasileiro de Apoio às Micro e Pequenas Empresas (SEBRAE, 2018) corroboram o cenário positivo, com estimativa de crescimento de $5,6 \%$ na cadeia de valor e otimismo no setor.

Um dos setores que são referência no Brasil por seu clima tropical e praias paradisíacas é o setor de moda praia, visto que é responsável por movimentar muitos dos recursos no país (SEBRAE, 2018). Segundo dados da Revista Criativa, publicados no ano de 2012, o Brasil é o país que mais consome moda praia no mundo. 
Os dados apontam, ainda, que são movimentados 1,5 bilhões somente no mercado interno, conforme relato da Associação Brasileira de Indústria Têxtil (SEBRAE, 2018). O mercado de moda infantil representa uma oportunidade de expansão e crescimento no cenário brasileiro. Esse fato pode ser ilustrado no artigo de Cris Olivette para o jornal Estadão Olivette (2018). Em seis anos, o volume de venda anual de produtos do segmento infantil no Brasil passou de $R \$ 2,7$ bilhões para $R \$ 3,9$ bilhões.

Considerando esse contexto, pode-se notar que o crescimento de $45,6 \%$ foi apurado por estudo da agência de inteligência Euromonitor (2017). Somente nos últimos dois anos, a variação de crescimento foi de $8 \%$, dado que demonstra que mesmo durante a crise o segmento manteve certo fôlego (ESTADAO, 2018). Marcelo Prado, Diretor do IEMI Inteligência de Mercado, afirma que dentre os maiores países do mundo, o Brasil é um dos que tem maior número de crianças. (PRADO, 2018). Segundo Prado (2018), estimativas indicam que, em 2017, a produção de vestuário infantil e bebê, em termos de volume de peças, teve crescimento de 3,1\%. Em relação à receita, as estimativas mostram alta de $6,2 \%$ sobre 2016 . Tais dados justificam a importância da temática.

\section{METODOLOGIA}

A primeira etapa do trabalho foi uma visita à loja Zillê Rio em Ipanema para fazer uma entrevista com a dona da marca, Luiza Azambuja. O objetivo desta etapa foi questionar a possibilidade de realização do trabalho, o acesso à loja e aos funcionários assim como conhecer a história que há por trás da marca. Além disso, foi possível observar o ambiente da loja, incluindo a decoração, o estoque, o processo de venda e o tratamento com os clientes. Foi preparado um roteiro com perguntas a serem feitas em relação ao histórico da Zillê (e a trajetória da empreendedora). Essa entrevista foi realizada no dia 4 de abril de 2019 e durou cerca de 2 horas. No mesmo dia, foram realizadas entrevistas com as duas funcionárias da loja: a designer e outra da área comercial. Elas relataram o que fazem no seu cotidiano e suas funções na loja.

Realizou-se um trabalho de campo com o público-alvo sugerido pela gestora da empresa: mulheres acima de trinta anos. Este grupo foi dividido em: mulheres entre 
trinta e trinta e nove anos, quarenta e quarenta e nove anos e mulheres acima de cinquenta. Como a gestora também planeja uma coleção "mães e filhos", foi registrado se as mulheres possuíam filhos. A pesquisa com clientes foi realizada no período de 4 de abril a 1 de maio de 2019. A seleção de sujeitos foi por acessibilidade. As entrevistadas foram as potenciais clientes do público-alvo que a marca almeja alcançar, moradoras do Rio de Janeiro, pertencentes às classes $A$ e $B$ e consumidoras de moda praia. As entrevistas foram realizadas em dias e horários alternados, por telefone ou pessoalmente, seguindo o roteiro pré-estabelecido. Foram entrevistadas vinte pessoas, correspondendo a mulheres distribuídas nas três faixas etárias supracitadas.

As entrevistadas que possuem filhos responderam à segunda parte da entrevista, destinada às mães. A ferramenta utilizada para elaborar o roteiro foi o Google Forms. Algumas entrevistas foram presenciais e gravadas com autorização das respectivas entrevistadas. Outras foram realizadas por Skype ou telefone e as anotações feitas seguiram a ordem das perguntas no roteiro. O tempo estimado foi cerca de dez minutos por pessoa. As entrevistas foram tanto presenciais quanto feitas por telefone. Os dados foram analisados de forma qualitativa, divididos de acordo com os subtipos do público-alvo. Existem quatro tipos de produtos vendidos pela Zillê: maiôs (carro chefe da marca), biquínis, saídas de praia e acessórios como lenços, colares, brincos e pulseiras. A distribuição é feita de duas formas: loja física e compras online, que são despachadas por correio.

As entregas são feitas em outros estados via contrato mantido com os correios, que buscam os produtos na loja em Ipanema, onde se localiza o estoque enviando-os aos destinatários. A comunicação para promover a marca é feita via redes sociais como Instagram, Facebook e pelo site. A Zillê usa essas ferramentas para divulgar os produtos e para atrair possíveis consumidoras. As clientes que compram com mais frequência recebem e-mails com cupons de desconto e avisos de promoções. As consumidoras de outros estados recebem um bilhete de agradecimento pela compra, objetivando o estreitamento de contato. Algumas clientes satisfeitas postam fotos nas redes sociais usando produtos da marca, com objetivo de atrair mais consumidoras e 
promover um feedback positivo à Zillê. O site e a página no Instagram são ferramentas úteis para divulgar os produtos, facilitando o contato das clientes que tenham interesse em comprar.

Ambos são bem ilustrados com fotos de modelos usando os produtos da marca. $\mathrm{O}$ site é organizado com um layout "clean", contendo as coleções por tipo de produto, possibilitando a consulta do preço de cada peça. A página possui ajuda e suporte com informações de dúvidas frequentes, como comprar e a respeito de troca e devolução de produtos. Segundo informações da Zillê Rio, as compras são feitas direto na loja ou pelo site, via cartão de crédito. Basta a cliente efetuar um cadastro, sendo possível parcelar em quantas vezes desejar. $O$ frete é calculado conforme a localidade e seu valor é adicionado automaticamente ao total de compras. O preço varia entre noventa a trezentos reais, dependendo da peça e é baseado na concorrência. A gestora mencionou, em sua entrevista, que administra a escala de entregas para todo o Brasil, delegando o controle a uma funcionária que administra o e-commerce da marca.

Ela sempre busca parcerias. Por exemplo, parceria com marca masculina para kit de dia dos namorados e o acréscimo da estampa da Zillê na roupa de outra marca com a finalidade de aumentar a divulgação e as vendas. Luiza mencionou que a organização já está com projeto para fazer uma coleção infantil de dia das mães e tem uma coleção de bermudas masculinas estampadas. Finalmente disse que as oportunidades que gostaria de explorar estão relacionadas a marketing digital (campanhas no Google Adds), moda infantil e para um público mais velho. Logo depois da entrevista com Luiza Azambuja, foi realizada a entrevista com estagiárias da Zillê. Em uma viagem para um congresso de e-commerce em São Paulo anotou vários insights com objetivo de melhorar o Instagram e o site da marca. No estudo de caso foi apurado que as funcionárias fazem muitas pesquisas para aprender como anunciar de forma adequada nas redes sociais.

A designer da marca aceita pedidos de itens inexistentes no estoque, pois como a Luiza vai para confecção dois dias na semana facilita a fabricação de peças por encomenda. A proprietária comentou que por isso conseguem vender uma quantidade maior de peças do que possui no estoque. As peças por encomenda demoram um dia 
para ficarem prontas. Esse processo otimiza a quantidade de peças no estoque, que tem um volume pequeno e agiliza a entrega para clientes que moram em outros estados. A divisão em faixas etárias foi feita para saber como cada mulher reage a um item específico do mix de marketing e que fatores são prioritários para o consumo. Além disso, foi determinada com base no estudo de caso da Zillê que contêm relatos das funcionárias e gestora, visto que presenciaram hábitos de consumo semelhantes dentro das faixas etárias apresentadas.

Assim sendo, percebe-se que mulheres entre trinta e trinta e nove anos preferem peças mais baratas e ainda que essas compram online ou presencialmente. A forma de promoção que mais atrai esse público é o meio digital ou vitrines e os produtos de preferência são maiôs e biquínis de modelos mais modernos e com estampas alegres. Já as mulheres entre quarenta e quarenta e nove preferem peças mais caras, têm tendência a comprar presencialmente, são atraídas por promoção em vitrines de lojas e priorizam o conforto, qualidade do tecido e modelos mais tradicionais. As mulheres acima de cinquenta optam, também, por peças mais caras e devido à sua estabilidade financeira, compram presencialmente, são atraídas por promoções em vitrines de lojas e priorizam modelos sem muita estampa, que tenham conforto e durabilidade.

Geralmente, as mulheres na faixa etária entre trinta e trinta e nove anos possuem filhos menores de até seis anos e essas mães também compram as roupas de banho das suas crianças na mesma loja, caso tenha modelos infantis. Existem aquelas que gostam de usar roupas parecidas ou iguais às de seus filhos. Já as mães que têm filhos acima dessa faixa etária não apreciam tanto roupas de banho semelhantes. Por último, foi realizada a entrevista com clientes para avaliar os seus hábitos de consumo frente ao mix de marketing. Ao analisar o relatório com as entrevistas das clientes, optou-se por dividir os resultados em cinco categorias. Dentre as marcas de preferências citadas temos Salinas, Blue Man, Lenny e outras marcas vendidas online ou em lojas físicas. Entre os critérios de compra citados temos corte, tecido, estampa, preço, qualidade, modelo e durabilidade. As respostas em relação ao tipo de peça de moda praia que as mulheres usam inclui saída de praia, maiô e biquíni. 
O modelo de biquíni que as entrevistadas apontaram em comum refere-se à parte de cima estilo "cortininha", parte de baixo com laço nas laterais para as mulheres entre trinta e trinta e nove anos ou sem laço com tamanho médio para mulheres de quarenta a quarenta e nove anos. Os tecidos de preferência foram lycra, poliamida e com proteção contra raios UV. Em relação ao maiô, as respostas incluíram modelos com ou sem estampa, não muito cavados e confortáveis no corpo, sem muitos detalhes para evitar marcas indesejadas, principalmente entre as mulheres acima de cinquenta. As saídas de praia, segundo as entrevistadas, devem combinar com a roupa de banho, seja biquíni ou maiô, na estampa ou no tom de cor caso for lisa. As entrevistadas que falaram isso frequentam outros eventos como churrascos e passeios de barco, que remetem ao estilo praiano.

\section{RESULTADOS}

A partir dos relatos das entrevistadas, a seção de resultados foi organizada de acordo com o mix de marketing: produto, preço, praça e promoção. No que se refere a produto, nota-se nas entrevistas realizadas que as clientes variam entre o uso de biquínis, maiôs e saídas de praia e gostam de combinar esses produtos com acessórios como brincos, colares, pulseiras e anéis também vendidos pela marca Zillê. A preferência por modelos desses produtos varia de acordo com a faixa etária das entrevistadas, estilo de vida, poder aquisitivo, gostos e se possuem filhos ou não. Não há relação entre perfil e tipo de estampa, visto que depende da preferência de cada cliente. Essas peças variam em modelo de preferência independente da faixa etária. Algumas mulheres disseram preferir modelos mais cavados nas laterais, outras optam por menos cavados e mais lisos.

Quanto ao tecido, uma parte das entrevistadas prefere cores neutras e lisas, outras com estampas delicadas e não muito chamativas. As mais modernas gostam de modelos mais contemporâneos com fendas na parte do abdômen e com várias tiras na alça e na parte de trás das costas e decote profundo. As consumidoras usam roupa de banho em suas viagens para lugares de praia. Essas mulheres costumam combinar as três peças citadas em passeios de barco e, também, para frequentar quiosques à beira da praia, mesmo que não entrem no mar. Há algumas que usam na 
piscina e em eventos como churrascos e pool party. Os acessórios são secundários quando se trata de sua aquisição por parte das entrevistadas. Algumas preferem tomar sol sem nenhum acessório por não gostarem da marca que eles deixam.

Outras gostam de combiná-los com os produtos mencionados (biquíni, maiô e saída de praia) para compor seu visual. Nas entrevistas, notou-se que modelos que não marcam muito o corpo são preferência para mulheres entre quarenta e quarenta e nove anos. As mulheres com filhos optam por roupas iguais para mães e filhos só até a faixa etária de seis anos, após a qual, segundo o relato das mães, a criança quer preservar sua individualidade. Estampas variadas e alegres agradam especialmente as mulheres de trinta a trinta e nove anos. Corte e tecido de qualidade e macio, que atenda critério de durabilidade, conforto e preço acessível são preferência geral das três faixas etárias. Modelos com cores neutras e não muito cavados também chamam a atenção. Estampas atemporais e com um quê de moderno são as preferidas das mulheres com quarenta até quarenta e nove anos.

Preferem, ainda, modelos clássicos que não destoem do seu padrão de consumo. As mulheres nessa faixa etária preferem peças com proteção na parte dos seios, espuma pequena, bojo e sustentação de arame. Na parte de baixo, corte médio, não muito cavado, mas também não muito largo. As atletas de qualquer faixa etária apresentada que praticam atividade física como corrida na beira da praia optam por modelos adequados para prática de esporte, com tecido flexível. As mulheres acima de cinquenta anos não gostam de roupas que remetam ao aspecto de idosa. Preferem modelos modernos, que valorizem outras partes do corpo como colo, por exemplo. Elas prezam por peças que afinem a cintura e que sustentem de maneira firme os seios e os glúteos. O preço varia, sendo uma média dos relatos das entrevistadas e, também, baseado na fonte da loja Zillê, analisada no estudo de caso.

Os biquínis custam na faixa de cem a duzentos reais, já os maiôs entre duzentos e trezentos reais e as saídas de praia até quatrocentos reais. A faixa de preço estipulada é baseada na concorrência e leva em consideração o custo de fabricação de cada peça, a criação de tecidos, o pagamento de funcionários e a entrega para outras localidades. As pessoas que podem pagar esse preço correspondem a mulheres das 
classes $A$ e $B$, que ganham mais que $R \$ 9.370,01$ e moram na zona sul do Rio de Janeiro. Em relação à praça, constata-se que as clientes compram online, presencialmente e de acordo com as faixas etárias. As mulheres de trinta a trinta e nove anos compram tanto online como presencialmente, as de quarenta a quarenta e nove anos mais presencialmente do que online e as acima de cinquenta compram de forma presencial na própria loja.

A promoção é um item importante do mix de marketing. As entrevistadas responderam que gostam da experiência de provar o produto na loja, porém ainda compram online. Outras já acham perda de tempo e por saberem seu tamanho e modelo de agrado optam apenas por compra online. Já o público mais tradicional e não muito ligado a tecnologia compra somente na loja, pois sente necessidade de testar a qualidade do produto pessoalmente. Essas respostas não têm um padrão por faixa etária e variam de acordo com o estilo de vida de cada pessoa. O que faz as consumidoras comprarem uma nova roupa de moda praia pode ser as suas estarem gastas ou velhas, mas também o fato de gostarem de um produto visto na vitrine ou um anúncio que desperte sua vontade de comprar. Isso pode ser explicado em função da identificação com a peça e da necessidade do momento.

As respostas citadas em relação à frequência de compra das roupas variam de uma vez ao ano até de dois em dois meses. Esses prazos foram dados de acordo com as características de consumo, estilo de vida e situação financeira de cada entrevistada. As entrevistadas descobrem novas marcas de moda praia por intermédio das redes sociais como o Instagram e, também, em passeios esporádicos na rua quando veem vitrines em shoppings, galerias e em lojas de rua. $\mathrm{O}$ que faz as consumidoras mais dispostas a experimentarem novas marcas é: a marca combinar com seu estilo, o conforto, a estampa, o modelo, o corte e a proposta de venda de cada uma. Após as entrevistas foi constituída a Tabela 1 que é um resumo do comportamento dessas consumidoras frente ao mix de marketing. A tabela revela todos os dados dispostos nesta investigação. 
Tabela 1 - Comportamento das consumidoras frente ao mix de marketing

\begin{tabular}{|c|c|c|c|c|}
\hline $\begin{array}{l}\text { FAIXA } \\
\text { ETÁRIA }\end{array}$ & PREÇO & PRAÇA & PROMOÇÃO & PRODUTO \\
\hline 30 à 39 anos & $\begin{array}{l}\text { Optam por } \\
\text { peças mais } \\
\text { baratas }\end{array}$ & $\begin{array}{l}\text { Compram online } \\
\text { e presencial }\end{array}$ & $\begin{array}{l}\text { Atraídas por } \\
\text { anúncios } \\
\text { digitais e } \\
\text { vitrines de loja }\end{array}$ & $\begin{array}{l}\text { Interessadas } \\
\text { em design } \\
\text { moderno }\end{array}$ \\
\hline 40 à 49 anos & $\begin{array}{l}\text { Optam por } \\
\text { peças com } \\
\text { preço } \\
\text { mediano }\end{array}$ & $\begin{array}{l}\text { Compram menos } \\
\text { online e mais } \\
\text { presencialmente }\end{array}$ & $\begin{array}{l}\text { Pouco } \\
\text { atraídas por } \\
\text { anúncios } \\
\text { digitais e mais } \\
\text { por vitrines de } \\
\text { loja }\end{array}$ & $\begin{array}{l}\text { Priorizam } \\
\text { qualidade e } \\
\text { conforto }\end{array}$ \\
\hline $\begin{array}{l}\text { acima de } 50 \\
\text { anos }\end{array}$ & $\begin{array}{l}\text { Optam por } \\
\text { peças caras }\end{array}$ & $\begin{array}{l}\text { Raramente } \\
\text { compram online } \\
\text { e mais } \\
\text { presencialmente }\end{array}$ & $\begin{array}{l}\text { Mais atraídas } \\
\text { por anúncios } \\
\text { em vitrines }\end{array}$ & $\begin{array}{l}\text { Preferem } \\
\text { design } \\
\text { tradicional }\end{array}$ \\
\hline
\end{tabular}

Fonte: Elaborado pela autora (2020).

\section{CONSIDERAÇÕES FINAIS}

Foi identificado o público de acordo com o estudo de caso da marca de moda praia Zillê, baseado nas entrevistas com a gestora, que almeja expandir a marca para esse público e com as funcionárias, sendo possível dividir esse público três perfis por intermédio de suas faixas etárias: mulheres entre trinta e trinta e nove anos, quarenta e quarenta e nove anos e acima de cinquenta anos. A partir desses dados, traçou-se os hábitos de consumo das três faixas etárias apresentadas no que se refere ao mix de marketing. Dentre eles destacam-se:

- Quanto ao preço: constata-se variação no que o perfil está disposto a pagar em função de sua classe social, faixa etária e estilo de vida; 
- Sobre a praça: constata-se que as mulheres entre trinta a trinta e nove anos compram tanto presencialmente como online, as de quarenta a quarenta e nove anos compram mais presencialmente que online e mulheres acima de cinquenta compram somente de maneira presencial;

- Em relação à promoção, mulheres de trinta a trinta e nove anos respondem bem aos anúncios de digital influencers, as de quarenta a quarenta e nove anos sentem-se mais atraídas por anúncios online em revistas femininas tradicionais e também por vitrines de loja e as mulheres acima de cinquenta são mais atraídas por anúncios em vitrines; e

- Sobre o produto, as mulheres entre 30 a 39 anos são interessadas em design moderno, as de 40 a 49 anos priorizam qualidade e conforto e as acima de cinquenta anos preferem design

Notou-se que mulheres com filhos até seis anos costumam comprar peças semelhantes e na mesma loja para eles. Esse hábito não se repete no caso de filhos maiores de 6 anos. Fica em aberto para trabalhos futuros avaliar o mix de marketing em relação a mulheres abaixo de 30 anos, já que o escopo deste era mulheres acima de 30 anos.

\section{REFERÊNCIAS}

ALANCA, D. História social da moda. Tradução de Renata Ambrósico. São Paulo: Ed. Senac, 2008, p. 11-12.

ELIAS, J. J. Marketing: o modelo dos 4ps. 2000. Disponível em: http://adm.cneccapivari.br/?q=node/20. Acesso em: 29 out. 2019.

EUROMONITOR. Mercado Infantil. Rio de Janeiro, 2017. Disponível em: https://economia.estadao.com.br/blogs/sua-oportunidade/mercado-infantil-exigediferencial-e-foco/. Acesso em: 13 abr. 2019. 
FIRJAM. Dados do setor de moda e empregabilidade. Rio de Janeiro, 2018. Disponível em: http://agenciabrasil.ebc.com.br/economia/noticia/2018-10/setor-damoda-deve-crescer-no-rio-56-ate-2023-diz-sebrae. Acesso em: 27 mar. 2019.

GARCIA, C. O biquíni - uma verdadeira bomba. Disponível em: http://almanaque.folha.uol.com.br/biquini.htm. Acesso em: 30 out. 2019.

GONÇALVES, F. P. S. et al. O Impacto das Certificações de RSE sobre o Comportamento de Compra do Consumidor. In: ENCONTRO NACIONAL DA ASSOCIAÇÃO NACIONAL DOS PROGRAMAS DE PÓSGRADUAÇÃO EM ADMINISTRAÇÃO, 32., 2008, Rio de Janeiro. Anais... Rio de Janeiro: ANPAD, 2008.

KOTLER, P. Administração de Marketing: análise, planejamento, implementação e controle. 5ª. ed. São Paulo: Atlas, 1998.

MARQUES, C. T. Potencialidades e limitações da aplicação simultânea de aromas e de pigmentos sensíveis ao calor e à luz em artigos de moda praia. 144 f. 2004. Dissertação (Mestrado em Design e Marketing). Universidade do Minho, Portugal, 2004.

MANEQUIM. A história do Biquíni. Disponível em http://manequim.abril.com.br/moda/historia-da-moda/. Acesso em: 30 out. 2019.

NICKELS, W. G.; WOOD, M. B., Marketing: relacionamentos - qualidade - valor. Rio de Janeiro: LTC, 1999.

OLIVETTE, C. Mercado Infantil exige diferencial e foco. Rio de Janeiro, 2018. Disponível em: https://economia.estadao.com.br/blogs/sua-oportunidade/mercadoinfantil-exige-diferencial-e-foco/. Acesso em: 13 abr. 2019.

PRADO, M. Dados Inteligência de mercado do setor infantil. Rio de Janeiro, 2018. Disponível em: https://economia.estadao.com.br/blogs/sua-oportunidade/mercadoinfantil-exige-diferencial-e-foco/. Acesso em: 13 abr. 2019. 
REVISTA CRIATIVA. Dados do setor de moda. Rio de Janeiro, 2012. Disponível em: http://revistacriativa.globo.com/Revista/Criativa/0,,EIT0-17122,00.html. Acesso em: 27 mar. 2019.

RODRIGUES, L. Setor de Moda deve crescer no Rio. Rio de Janeiro, 208. Disponível em: http://agenciabrasil.ebc.com.br/economia/noticia/2018-10/setor-damoda-deve-crescer-no-rio-56-ate-2023-diz-sebrae. Acesso em: 27 mar. 2019.

SEBRAE. Varejo Moda Praia. Rio de Janeiro, 2014. Disponível em: http://www.sebraemercados.com.br/wpcontent/uploads/2015/10/2014_06_04_BO_V arejo_Abr_ModaPraia_pdf.pdf. Acesso em: 27 mar. 2019.

Enviado: Dezembro, 2019.

Aprovado: Março, 2020. 